\title{
E1 sindicalismo empresarial en los años 90. Una aproximación desde su materialidad
}

\author{
Julieta Haidar
}

IIGG-UBA

En los años 90, en medio de la escalada neoliberal y la implementación de las reformas de mercado, un grupo de gremios históricamente poderosos, como los de construcción, comercio, sanidad, electricidad, adoptaron la estrategia conocida como "sindicalismo empresarial", esto es, participaron en los negocios habilitados por las reformas: adquirieron empresas privatizadas, formaron aseguradoras y administradoras de fondos previsionales, entre otros emprendimientos.

Esa estrategia fue interpretada por la literatura especializada desde distintos enfoques que, en forma dominante, tendieron a señalar los rasgos de continuidad con viejas prácticas de negociación y pragmatismo propios de la burocracia sindical. Aquí consideramos que tales enfoques son reduccionistas y que no logran dar cuenta de la naturaleza ni de la especificidad de la estrategia que, a priori, constituye un oximoron: aquel que se da entre trabajo y capital.

El estudio en profundidad de Luz y Fuerza Capital Federal (LYF CF), sindicato que fue paradigmático en el impulso de los negocios de mercado, nos llevó a formular la tesis de que el sindicalismo empresarial no fue una respuesta continuista sino una etapa específica en el modo en que la organización se reproduce materialmente.

En este marco, con la intención de aportar al debate acerca de los sentidos del fenómeno y de las dimensiones que intervienen en la definición de las estrategias gremiales, en este artículo en primer término vamos a revisitar criticamente las interpretaciones dominantes sobre el sindicalismo empresarial y a plantear las principales líneas teóricometodológicas de nuestra propuesta, para luego avanzar en el análisis teórico y empírico de los emprendimientos promovidos por LYF CF.

Para llevar a cabo esta investigación, que tiene un carácter cualitativo, utilizamos como fuentes principales los convenios colectivos de trabajo firmados por LYF CF y las revistas Dinamis del gremio entre 
1943 y 2003, los artículos periodísticos con que cuenta el archivo de prensa de la organización desde el año 1989, Tendencias económicas del Ministerio de Economía de la Nación (1990-2003), las revistas Contacto de la FATLYF (1990-2003) y los informes sobre composición empresaria en el sector eléctrico provistos por el ente regulador, ENRE (1993-2003). Este corpus se completa con entrevistas realizadas en el año 2013 a los miembros de la comisión directiva de LYF CF.

\section{Las interpretaciones sobre el sindicalismo empresarial}

En un trabajo anterior (Haidar, 2015b) reconocimos la existencia de tres enfoques dominantes que entendieron al sindicalismo empresarial como: una adaptación del sindicalismo corporativo y burocrático (De la Garza, 2001; Novick, 2001; Martuccelli y Svampa, 1997), una respuesta innovadora producto de la negociación con el gobierno (Murillo, 1997, 2001; Etchemendy, 2001), una forma de "business unionism" (Ranis, 1995; Novick, 1996, 2001; Palomino, 1999).

El primer enfoque entendió que, ante la emergencia de las reformas neoliberales y con un nuevo modelo de relaciones laborales orientado hacia la precarización del empleo, la descentralización de la negociación colectiva y la desindicalización, la estrategia general de los sindicatos corporativos consistió en tratar de adaptarse y reconstruir su alianza con el Estado (De la Garza, 2001).

En esta dirección, Novick (2001) señaló que en los años 90, ante el retiro del Estado y la desarticulación de los institutos laborales, se alteró la identidad del modelo de organización sindical, y los gremios que permanecieron en la conducción de la CGT reaccionaron en forma corporativa, intentando mantener el poder y la identidad a través de viejos mecanismos como el diálogo, la negociación y el pragmatismo. La tendencia a la burocratización desembocó en la cristalización de las estructuras burocráticas, con un control férreo de las dirigencias sobre las comisiones de delegados, a través del disciplinamiento y la cooptación, vía acción patoteril, ofrecimiento de cargos y nuevos servicios, que conformarian la modalidad del sindicalismo empresarial (Martuccelli y Svampa, 1997).

En otros términos, para este enfoque la estrategia fue una respuesta conservadora adaptativa, en la que el eje del intercambio y la negociación politica de los dirigentes sindicales fue el resguardo de sus prerrogativas y el modelo organizacional, en línea con viejos estilos y mecanismos propios de un sindicalismo corporativo y burocrático.

Para la segunda línea interpretativa (que no se opone a la anterior sino que sobre los mismos supuestos desarrolla otra tesis) el sindica- 
lismo empresarial fue una respuesta innovadora producto de la negociación con el gobierno. En este camino, Etchemendy (2001) avanzó en la idea de que el Estado construyó coaliciones valiéndose de una politica de compensaciones que consistieron en la desregulación parcial y la asignación directa de rentas. Frente a los costos de los aumentos salariales atados a la productividad, la desocupación y los acuerdos colectivos flexibles, los sindicatos obtuvieron, por una parte, un limite a la desregulación, ya que lograron preservar el monopolio de la representación y la negociación centralizada, mantener la ultraactividad de los viejos convenios y limitar la desregulación de las obras sociales. Por otra parte, consiguieron una asignación directa de rentas que implicó la participación en la jubilación privada y en las ART, la administración de las acciones en las empresas privatizadas a través del programa de propiedad participada (PPP) y activos del Estado.

Pero fue Murillo $(1997,2001)$ quien más avanzó en la interpretación del fenómeno desde la relación entre las organizaciones gremiales y el Estado. Ella coincide en que la regulación laboral corporativista había contribuido a controlar a los sindicatos desde el Estado y a facilitarles la creación de instituciones (recursos políticos) para resolver más favorablemente el conflicto industrial, en vez de depender de la movilización obrera y las condiciones del mercado laboral (recursos industriales). Las reformas de los 90 vinieron a golpear este esquema ya que disminuyó el número de afiliados, cambiaron las instituciones laborales y los sindicatos perdieron influencia en el Partido Justicialista, todo lo cual restringió su capacidad de acción y movilización.

La supervivencia organizativa, nombre que dio al involucramiento en actividades empresariales, fue una respuesta que según Murillo no constituyó una automática adaptación conservadora, sino una estrategia innovadora que buscó disminuir la histórica dependencia del Estado como fuente de recursos organizativos y reemplazarla por mecanismos de mercado promovidos por las reformas.

Uno de los puntos que se destacan en esta argumentación es que la caída de las cuotas sindicales y las contribuciones de las obras sociales, fue compensada con ingresos derivados de actividades empresarias destinadas a consumidores en general. Es decir, los gremios optaron por una estrategia de inversión en nuevos recursos para poder sobrevivir organizativamente.

Entendemos que esta interpretación se orientó a destacar los componentes innovadores del sindicalismo empresarial, pero asumiendo la caracterización de un tipo de sindicalismo corporativo y burocrático cuyo objetivo primordial es preservar la estructura.

Por último, el tercer enfoque identificó al fenómeno con la configuración del modelo de "business unionism", en que el sindicato amplía 
sus actividades de provisión de servicios hasta alcanzar funciones empresarias (Ranis, 1995).

En esta linea Palomino (1999), en sintonía con las interpretaciones anteriores, entendió que la participación de los sindicatos en los negocios habilitados por las privatizaciones de empresas, las reformas previsional y de seguros por accidentes de trabajo, fue una concesión otorgada por el gobierno a cambio del apoyo a las mismas y que las reformas reforzaron la brecha existente entre el aparato sindical y los trabajadores. Enfatizó además que los dirigentes utilizaron la representación para vender servicios a sus propios representados, que pasaron a ser clientes cautivos. Asimismo Novick (1996) señaló que los sindicatos se convirtieron en empresas gestoras o en verdaderos holdings empresariales teñidos de una relación instrumental y económica con los trabajadores.

En otros términos, esta línea interpretó al sindicalismo empresarial como una continuidad y fortalecimiento de la identidad del sindicato asociada a la prestación de servicios sociales.

Haciendo un balance de estos tres enfoques consideramos que los mismos realizaron importantes aportes al estudio de la estrategia. Analizaron las relaciones de los actores con el Estado y, en este sentido, contribuyeron a desentrañar los procesos de negociación, concesión e intercambio por los cuales un grupo de sindicatos participaron en los negocios abiertos por las reformas de mercado. Ponderaron también la gravitación de los distintos recursos de poder así como de los legados institucionales, lo que contribuyó a identificar cuáles fueron los gremios que adoptaron esta estrategia.

Además -si bien en forma marginal- estas interpretaciones reconocieron la dimensión económica del sindicalismo empresarial, sea como contrapartida a la caída de las cuotas sindicales y de las contribuciones de las obras sociales (Murillo), como compensación general en forma de renta (Etchemendy) o como mercantilización de la relación entre afiliados y sindicatos (Ranis, Palomino).

No obstante, advertimos que estos enfoques poseen una debilidad común y es que tienden a reducir la estrategia a una continuidad con viejos estilos, prácticas u objetivos institucionales. Este procedimiento es claro en el caso de la primera línea interpretativa, ya que catalogó al fenómeno como una respuesta conservadora-adaptativa de un modelo organizacional. También en el enfoque que vio en el sindicalismo empresarial una extensión y profundización de la función sindical de provisión de servicios sociales, con lo cual la diferencia entre ambos términos sería sólo de grado. Pero aún en el caso de Murillo prima la clave continuista, ya que si bien señaló el carácter innovador de la estrategia, para ella el objetivo no puede ser otro que preservar la organización (el aparato) sólo que a través de nuevas fuentes de recursos organizacionales que le 
permitan disminuir su dependencia respecto del Estado, actor central en los análisis.

Estas producciones, al concentrarse en identificar continuidades político-institucionales no consiguieron detectar la singularidad del sindicalismo empresarial. En otra dirección, un grupo de investigaciones en las que participamos (Ghigliani, 2009; Haidar, 2010; Ghigliani, Grigera y Schneider, 2012; Ghigliani y Haidar, 2013; Haidar, 2015b) entendió que para poder captar el fenómeno en su complejidad y particularidad había que analizar una nueva dimensión que aludiera a la vida material de los gremios y además que había que hacerlo en perspectiva histórica.

En este marco introdujimos la categoría de mecanismos sindicales de reproducción material (MSRM) definidos como "los mecanismos que expresan las relaciones sociales a través de las cuales las organizaciones gremiales se reproducen económicamente" (Haidar, 2015a: 19). Esta dimensión refiere al sostenimiento y expansión económica de los sindicatos, lo que no implica un interés por su microeconomía, sino que la lectura de los mecanismos reproductivos en términos de relaciones sociales busca apartarse de una perspectiva economicista, descosificar la problemática y situarla en una dimensión productiva y política, bajo el supuesto de que la expansión y contracción económica de un gremio expresan relaciones sociales de lucha.

Entendimos asimismo que en esa lucha los mecanismos reproductivos pueden adoptar históricamente distintas características, asociadas a la complejidad (las relaciones sociales pueden ser más o menos complejas en función de las mediaciones que intervienen en la obtención de recursos), a los efectos sobre la estructura organizacional y patrimonial del sindicato (en determinado momento histórico los mismos pueden ser expansivos o contractivos), a la relación con la reproducción material de los trabajadores representados (el modo en que el sindicato se sostiene económicamente puede estar más o menos articulado con la función de contribuir a la reproducción material de sus representados) (Haidar, 2015a).

Las transformaciones en tales características son las que permiten periodizar la vida material de una organización sindical y detectar las especificidades que la misma va asumiendo en cada etapa histórica, siendo el sindicalismo empresarial una de ellas. En esta línea, el abordaje empírico y teórico del caso de LYF CF permite evidenciar cómo opera la materialidad en la definición de una estrategia gremial.

\section{El estudio de Luz y Fuerza Capital Federal. Los emprendimientos empresarios como MSRM}

Luz y Fuerza Capital Federal es el mayor gremio de trabajadores de 
la energía eléctrica, un sector que es fundamental para el desarrollo económico por su capacidad de potenciar las fuerzas productivas y contribuir a la producción de plusvalía. Estas condiciones llevaron a que los trabajadores de la rama formen parte de la fracción más acomodada de la clase, una aristocracia obrera cuyos niveles salariales son superiores al promedio del salario de los obreros industriales (Iñigo Carrera, Grau y Martí, 2006).

LYF CF es el sindicato más poderoso y el conductor político de la federación nacional (FATLYF) debido a que históricamente ha representado a los trabajadores de las empresas eléctricas más importantes (CIADE, CADE, luego SEGBA), lo que lo dotó del mayor número de afiliados y de los mejores convenios colectivos del sector. En los años 90 fue el promotor de la estrategia empresarial que la Federación ejecutará a partir de 1993, tras la expulsión del opositor sindicato de LYF Mar del Plata y la aprobación en el congreso federativo de 1992 de un detallado plan empresario que incluía participar en farmacias y droguerias, administradoras de fondos jubilatorios, compañias de seguros, agencias de turismo, empresas de energía y entidades bancarias, entre otras sociedades.

La FATLYF concretó la mayoría de estos proyectos y LYF CF, si bien realizó una incursión menor en la conformación de unidades de negocio (emitió los tickets canasta "Lyfcheck" e intentó sin éxito administrar los PPP y lanzar una tarjeta de crédito), ocupó un rol central en el proceso que protagonizó la Federación. Siendo su conductor político, impulsó la iniciativa, negoció políticamente su aprobación y aportó su patrimonio como garantía.

La FATLYF y LYF CF presentaron este plan como el producto de una continuidad lógica con lo que hacia mediados del siglo XX las propias organizaciones habian denominado como "sindicalismo múltiple", una concepción según la cual el sindicato no sólo debe luchar por mejores salarios y condiciones de trabajo, sino que también debe proveer múltiples servicios sociales a los afiliados y sus familias.

En Argentina la preocupación por el bienestar social de los afiliados encuentra como experiencias iniciales el auxilio reciproco que se prestaban los miembros de las asociaciones mutuales desde la segunda mitad de la década de 1850, a fin de atender las contingencias que los trabajadores en forma individual no podian resolver, como accidentes de trabajo y enfermedades (Falcón, 1984; Horowitz, 1988). Las funciones sociales de los sindicatos se intensificaron a partir de 1945 de la mano de un sistema de recaudación de aportes obligatorios que significaron una sólida fuente de ingresos, y de argumentos provenientes de la doctrina peronista y de la doctrina social de la Iglesia que se orientaban a sostener la integración y conciliación de clases. 
En los años 90 abundaron los discursos donde el llamado sindicalismo empresarial fue planteado como una proyección del sindicalismo múltiple tal como había sido entendido por el gremio eléctrico hacia mediados de siglo. Transcribimos uno de ellos:

Este es el sindicalismo múltiple, el gremialismo que pensó Perón en los 40. El sindicato no debe estar solamente en las trincheras de la confrontación, sino también para participar en las grandes politicas. Nosotros pensamos que no hay diferencia entre ser dueños de una cadena de hoteles o tener una usina. No hay diferencia entre manejar una obra social de 150.000 adherentes con tener una empresa de distribución. Acá la realidad del momento indica la transformación del sector eléctrico, nosotros somos actores directos sin desvirtuar nuestra filosofia. Somos una empresa privada con espíritu social. (Entrevista a Julio Ieraci, Noticias Gremiales n ${ }^{\circ} 302$, diciembre de 1994.)

La organización gremial colocó a los emprendimientos empresarios bajo el gran paraguas del sindicalismo múltiple, y en este sentido resulta significativo que uno de los enfoques más destacados dentro de la producción académica sobre el sindicalismo empresarial también haya interpretado la estrategia como una continuidad del "business unionism", entendiendo por tal a un tipo de sindicalismo que no sólo lucha por causas estrictamente gremiales, sino que además se ocupa de satisfacer las necesidades de sus afiliados, produciéndose así una convergencia entre la autorrepresentación de la organización y la interpretación académica.

El análisis de los emprendimientos empresarios, no ya en términos políticos, organizativos ni subjetivos, sino en clave material e histórica, permitirá resituar la estrategia y la pregunta sobre las continuidades y las transformaciones, la especificidad del fenómeno y sus motivaciones.

\section{Crisis y transformación}

A la luz del caso estudiado, nuestra hipótesis es que el sindicalismo empresarial conforma una etapa de desarrollo de la vida material de la organización, en la que emergen nuevos mecanismos reproductivos con características inéditas, que vinieron a remplazar a aquellos que -dominantes en una primera etapa- habian sufrido una crisis.

LYF CF transitó desde su fundación en 1943 hasta la intervención militar de 1976 un primer período de expansión de sus bases materiales, asentado en tres mecanismos: las cuotas de afiliación, los aportes extraordinarios realizados por los trabajadores a la firma de cada convenio y los aportes efectuados por los empresarios. 
Sujetos a los niveles de empleo, de salarios y a la dinámica de la negociación colectiva, tres determinantes que entre 1943 y 1976 tuvieron un comportamiento de tendencia ascendente, estas relaciones sociales que consideramos simples -por implicar transferencias directas de dinero, sin intercambio de mercancías- permitieron al gremio aumentar en forma exponencial sus ingresos.

En esta etapa el crecimiento del nivel de empleo/afiliación constituyó el determinante clave. LYF CF en diciembre de 1943 tenía 300 socios efectivos; en igual mes de 1944, 3.800; en diciembre de 1945, 8.600 y en junio de 1946, 11.500 (Dinamis, $\mathrm{n}^{\circ} 21$, julio de 1946). Veinte años después, el Secretario de Hacienda declaraba administrar el aporte de aproximadamente 28.500 afiliados activos (Dinamis, $\mathrm{n}^{\circ} 101$, septiembre de 1965) y para 1975 el dirigente Juan José Taccone informaba que los asociados eran 30.000 (Taccone, 1976).

Pero fueron los aportes empresarios fijados convencionalmente para formar los fondos sociales (colonia de vacaciones, vivienda, compensador, cultural y deportivo), ${ }^{1}$ los que representaron los mayores ingresos para el sindicato, siendo que desde que el mismo comenzó a controlarlos a partir de la firma del CCT de 1954, la alícuota se fue incrementando en forma progresiva hasta llegar a conformar el $7,5 \%$ de la masa salarial total en el CCT de 1975.

La magnitud del dinero recibido en concepto de fondos sociales implicó la posibilidad cierta de movilizarlo en circuitos de mayor complejidad. Uno de los más significativos fue el depósito bancario a cambio de intereses, lo que permitía obtener más recursos y/o evitar los efectos devaluatorios de la inflación. Otro circuito, vinculado a las funciones asignadas a los fondos, se organizó en torno a la venta de mercancías a los afiliados a través de las estructuras cooperativas (vivienda, seguros, crédito y consumo).

Detrás de estas operaciones estaba la concepción del "sindicalismo múltiple" referida antes: el sindicato debía atender la vida del trabajador y su familia desde que nace hasta que muere. Bajo este concepto participó en relaciones sociales más complejas que ya no implicaron

1. Un rasgo relevante del caso bajo estudio es que hasta la privatización de SEGBA LYF CF no tuvo una obra social propia, una fuente de recursos de capital importancia para los gremios argentinos, sobre todo a partir del reordenamiento del sistema en 1970. Por el contrario, la cobertura médica estaba a cargo de las empresas bajo el concepto de Servicios de Asistencia Sanitaria. Cuando se privatizó SEGBA, las nuevas empresas no quisieron hacerse cargo de la obra social que, dado el alto nivel de prestaciones que otorgaba y la baja de activos, resultaba deficitaria. Fue recién entonces que LYF CF junto con la Asociación de Personal Superior de Empresas de Energía Eléctrica formaron en 1992 la Obra Social de los Trabajadores de las Empresas de Electricidad (OSTEE). 
transferencias directas de dinero sino que se asentaron en su circulación. Sin embargo, es importante señalar que las mismas encontraron limites cuantitativos y cualitativos, ya que las ventas no trascendian a los propios afiliados y sus ingresos se destinaban al consumo de la organización. Esto tuvo un efecto expansivo que se cristalizó en el crecimiento del patrimonio, la sede social, los hoteles y los recreos. Las operaciones estaban destinadas a la satisfacción de las múltiples necesidades de la familia obrera (vivienda, créditos, ocio, etc.), a la cual quedaba subordinada la reproducción material del gremio.

Por lo tanto, las tres características prevalecientes en esta primera fase reproductiva de LYF CF fueron el sostenimiento de relaciones sociales simples y de otras más complejas asentadas sobre las anteriores, que implicaron la circulación del ahorro obrero pero no la personificación de capital; los efectos expansivos sobre el patrimonio gremial que significaron ampliar el fondo de consumo, y una estrecha articulación entre los MSRM y la reproducción de los trabajadores.

La dictadura militar de 1976 inauguró una segunda etapa, no ya de expansión sino de crisis en la vida material del gremio. Intervino las empresas de electricidad y el sindicato, suspendió primero y contrajo después los mecanismos reproductivos que habían sostenido la etapa anterior. Este proceso de crisis terminó de consolidarse con la privatización y fragmentación de SEGBA en 1992.

El empleo -principal determinante de los tradicionales MSRM- comenzó a descender en los prolegómenos de la privatización y, concretada la misma, cayó en forma brutal: en 1989 SEGBA empleaba a 22.809 trabajadores, en 1991 a 20.778, en 1992 (antes de la privatización) a 18.883, en 1993 a 10.976 y en 1998 a 6.837 (Duarte, 2001).

Si bien no disponemos de una serie completa de datos para el total de las empresas privadas en que se dividió SEGBA (cuatro generadoras y tres distribuidoras), Edesur -por su dimensión y por ser líder en las políticas del sector- se presenta como un caso testigo de la evolución del empleo. Mientras que en 1992 la empresa tenía 7.541 empleados, en 1993 pasó a 5.051 y continuó su descenso hasta 2002 en que llegó a registrar 2.251 trabajadores efectivos (Memoria y balance, Edesur, años 1992 a 2002).

A su vez, mientras se expulsaba a trabajadores de planta fue aumentando la cantidad de personal contratado por medio de terceras empresas, proceso que -tal como sucedió con el desempleo- se inició antes de la privatización. El gremio informaba que entre agosto de 1989 y mayo de 1990 la cantidad de contratados saltó de 181 a 482, mientras que los trabajadores efectivos se redujeron de 22.328 a 21.681 (Dinamis, $\mathrm{n}^{\circ} 36$, abril de 1992). La tercerización se profundizó luego con las gestiones privadas. Si bien los datos sobre las empresas 
contratadas son escasos, los dirigentes entrevistados sostienen que en los años 90 la cantidad de trabajadores contratados era igual a la de efectivos.

La contracción del empleo efectivo y la tercerización impactaron en forma directa en la afiliación de LYF CF, que pasó de 15.274 afiliados activos en 1992 a 11.724 en 1993 y continuó su descenso hasta llegar a 3.986 en 2002 (Secretaría de organización, LYF CF).

Este proceso tuvo graves impactos económicos sobre la organización ya que los ingresos recibidos por cuota de afiliación cayeron en forma proporcional, al tiempo que los aportes extraordinarios que efectuaban los trabajadores a la firma de cada convenio habian sido cancelados con la intervención militar, y los aportes empresarios para fondos sociales, principal mecanismo sobre el que se sostenía la economía gremial en el primer período, sufrieron una severa contracción.

A los efectos sobre la cuota de afiliación y los institutos de la negociación colectiva se agrega que la pérdida de puestos de trabajo impactó sobre las cooperativas, que en estos años se vieron desfinanciadas por la caída del número de socios y la dificultad para cobrar las cuotas adeudadas de aquellos que habían perdido su puesto de trabajo.

A partir de 1992 y a lo largo de la década, cada informe de la Secretaría de Hacienda daba cuenta del déficit crónico en que había entrado el gremio. Ante esta situación se imponía el dilema de cómo resolver un problema que afectaba no sólo su vida organizacional sino también sus fundamentos materiales. La respuesta más inmediata fue la reducción de gastos que se efectuó vía ajuste de las prestaciones a los afiliados. Junto con ello y fiel a su estilo realista y pragmático, acudió a herramientas como la concesión de parte de su patrimonio (los hoteles). Luego, habilitado por las reformas de mercado, elaboró una salida más compleja, la promoción de nuevos mecanismos reproductivos: los emprendimientos empresarios.

Esta decisión abrió una tercera etapa en la vida material del gremio que se extendió desde 1992, cuando el congreso ordinario de la Federación aprobó el plan empresarial, hasta 2003, cuando la misma instancia autorizó su desmantelamiento.

\section{Los negocios}

Entre 1993 y 2003 la FATLYF concretó casi todos los proyectos que diseñara en el congreso de 1992, convirtiéndose en un verdadero holding empresarial con la participación en más de veinte sociedades anónimas: cuatro generadoras (centrales térmicas NOA, Sorrento, Patagónica, Litoral), dos transportadoras (Transnoa, Transnea), dos distribuidoras (EJSED, EDESE), cuatro empresas de servicios (Sien, Andersen, Engion, 
Translyf), una productora de carbón (YC Río Turbio), una distribuidora de gas (Gasnea), un laboratorio (Laformed), una droguería (Medilyf), dos empresas de turismo (Volt's y TurLyfe), la AFJP Futura y dos aseguradoras asociadas: Fuerza (vida e invalidez) y Lúmina (renta vitalicia o jubilación programada), y la ART Luz.

Como hemos adelantado, desde nuestra perspectiva analítica este conjunto de negocios no constituyen otra cosa sino nuevos mecanismos reproductivos con características particulares que vinieron a remplazar a aquellos que -afectados sus determinantes- estaban en crisis.

Por primera vez en su historia el gremio estableció relaciones sociales mucho más complejas y utilizó el dinero proveniente del ahorro obrero con una nueva función y objetivo: constituirse en capital y valorizarse. Este proceso supuso el montaje de un complejo holding empresarial formado por unidades de negocios que operaban en múltiples esferas: comercial, financiera y productiva.

En cuanto a la esfera comercial, la iniciativa más clara fue la creación de la agencia de turismo Volt's que vendia paquetes, vuelos y plazas de la cadena de hoteles Intersur, propiedad de la Federación, y de la empresa TurLyfe destinada a la administración de sus hoteles y campos. Esta área que tradicionalmente constituyó un bastión de la función social del gremio, se transformó en una mercancía lanzada a un mercado que trascendia a la familia lucifuercista.

En esta etapa además el sindicato intervino como nunca antes en circuitos de capital financiero, esto es, el tipo particular de proceso de circulación que se centra en el sistema de crédito y la creación de formas ficticias de capital (Harvey, 1990). La FATLYF formó una complejísima estructura de negocios financieros: la AFJP, las aseguradoras satélites, la ART.

La novedad que trajo la AFJP fue la magnitud de la transferencia de recursos de los trabajadores hacia la esfera financiera en la que por definición se insertaba el negocio, tal como fuera diseñado el sistema integrado de jubilaciones y pensiones. Construida sobre la organización y los recursos del fondo compensador con que históricamente se pagaba el diferencial a los jubilados para que alcancen el $82 \%$ del salario de un activo, la Federación llegó a ser propietaria del 78\% de esta administradora que colocó el $100 \%$ de los fondos obreros en un conjunto heterogéneo de valores ficticios (títulos públicos, acciones, cédulas, etc.).

Las aseguradoras de vida (Fuerza), de renta vitalicia (Lúmina) y de riesgos del trabajo (Luz), también constituyeron estructuras financieras, aunque menores, que venían a complementar el porfolio de negocios creado en torno a la seguridad social.

El mayor proyecto financiero de la organización fue crear un banco, 
aspiración que no pudo concretar ${ }^{2}$ y que le hubiera permitido dejar de operar como un ahorrista que realiza depósitos a cambio de un interés para pasar a funcionar como un banco de ahorros.

Junto con el avance en la esfera comercial y financiera, la nota distintiva de esta etapa fue la incursión sistemática en el ciclo productivo del capital. En este orden una iniciativa menor fue la adquisición de un laboratorio farmacéutico (Laformed) y de una droguería (Medilyf). ${ }^{3}$ Muchos más ambiciosos en cambio fueron los emprendimientos energéticos que, en una muestra de la planificación que orientaba el proceso, se organizaron en tres áreas: los programas de propiedad participada (PPP), las inversiones genuinas y las empresas de mantenimiento.

En relación a la primera, la ley de reforma del Estado posibilitó que los trabajadores de las empresas privatizadas adquieran el $10 \%$ de las acciones clase $\mathrm{C}$ a través del llamado PPP y estableció que el manejo de las mismas debia ser sindicado (gestionado en forma colectiva) hasta que se complete su pago con las utilidades generadas. Dada esta posibilidad, la Federación se propuso ejercer la administración de las acciones de los trabajadores de las empresas eléctricas privatizadas, al tiempo que LYC CF inició una campaña a fin de que sus afiliados adhieran al programa y le otorguen su representación a través de la Cooperativa de Crédito, Consumo y Vivienda LYF Ltda.

El objetivo del sindicato era asumir lugares de conducción en los directorios y en un plazo más prolongado captar las acciones que se liberaban con el retiro de los trabajadores y que pasaban a un fondo de recompra. Si bien nada de esto se logró, el proyecto se dirigia a obtener una parte -aunque menor- de capital, una estrategia que se preveía complementaria a la adquisición de activos.

Con respecto a este último punto, dentro del holding empresarial ocuparon un lugar central las llamadas inversiones genuinas, adjetivación que remitía a la intervención directa en la esfera productiva. La Federación, lejos de resistir la privatización de empresas eléctricas, entre 1993 y 2003 participó activamente en las licitaciones de las unidades de negocio en que se dividieron Agua y Energía Eléctrica SE e Hidroeléctrica Norpatagónica SA (Hidronor). Es esta decisión de intervenir en las propias empresas a cuyos trabajadores representaba la que dio más

2. A mediados de 1993 la FATLYF ganó la preadjudicación del liquidado Banco Cooperativo Birco de la ciudad de Rufino, pero el Banco Central anuló la operación. Luego la Federación intentó comprar el banco de la provincia de Misiones, lo que tampoco se concretó (Clarín, 5 de marzo de 1994).

3. A fines de 1993 en un emprendimiento compartido con la provincia de Formosa, la FATLYF se quedó con la licitación del Laboratorio Formoseño de Medicamentos, Laformed SA, y en 1998 pasó a controlar la droguería Medilyf SA (Contacto, $n^{\circ}$ 54, octubre de 1993). 
visibilidad a la estrategia de sindicalismo empresarial que, sin embargo, trascendió largamente este negocio. El sindicato asumía un lugar dual en las relaciones sociales de producción: como representante de los trabajadores y como propietario de las empresas que los emplean.

En el lapso de diez años la Federación se constituyó como co-propietaria de cuatro centrales (NOA, Sorrento, Patagónicas, Litoral), dos transportadoras (Transnoa, Transnea) y dos distribuidoras (EJSED, EDESE); participó sin éxito de la licitación de seis empresas eléctricas (Centrales San Nicolás, Hidráulicas de Río Negro, Hidroeléctrica Diamante, Distrocuyo, EDEER, ESEBA); y por fuera de su actividad principal adquirió parte de la empresa productora de carbón (YC Río Turbio) y de una distribuidora de gas (Gasnea). ${ }^{4}$

Por último, la tercera área de los emprendimientos energéticos implicó la formación de empresas de mantenimiento. En esta dirección, por un lado, la FATLYF armó estructuras propias para proveer servicios a las compañias eléctricas ${ }^{5} \mathrm{y}$, por otro, organizó microemprendimientos, esto es empresas constituidas por los trabajadores que adhirieron a los planes de retiros voluntarios y que pasaron a prestar servicios como tercerizados, práctica que el sindicato no combatió (al menos no hasta el año 2000) sino que convalidó. ${ }^{6}$

Es de destacar que en los tres casos (PPP, inversiones genuinas, empresas de mantenimiento) las acciones de la Federación se orientaron a operar en la esfera productiva, la única que produce plusvalor. Así sus negocios alcanzaron todas las esferas de circulación del capital.

\section{Balance de la estrategia}

Una de las características centrales de los mecanismos reproductivos entre 1992 y 2003 es su nivel de complejidad, tanto en términos cuantitativos como cualitativos. En el primer sentido, la operación en los múltiples circuitos de capital en que se ubicaron las diversas unidades de negocio da cuenta de las dimensiones de la estrategia empresarial. La participación en decenas de licitaciones, así como el concepto mismo de holding, evidencian un proyecto orientado a maximizar las posibilidades de captar distintas formas de plusvalor.

4. La reconstrucción de la adquisición de acciones por parte de la FATLYF fue realizada en base a las revistas Dinamis y Contacto, el archivo periodístico de LYF CF, Tendencias Económicas del MECON y los informes sobre composición empresaria provistos por el ENRE (1993-2003).

5. Entre ellas se cuenta Sien SA, Engion SA y Translyf SA.

6. Para 1995, 290 trabajadores se agrupaban en 24 microemprendimientos que prestaban servicios a Edesur, Edenor y Central Puerto (Dinamis, $n^{\circ} 52$, mayo de 1995). 
Sumado a ello, la FATLYF atravesó los límites que el sistema de seguridad social concebido solidariamente le imponía, y pasó a operar en un mercado ampliado más allá de sus representados. Al mismo tiempo, habiendo virado el objetivo inmediato de la satisfacción de necesidades a la apropiación y generación de valor, la restricción de vender mercancías a los precios más bajos del mercado también desapareció.

Desde una perspectiva cualitativa, si bien la representación y la satisfacción de necesidades de los trabajadores siguió siendo, subjetiva y discursivamente, el horizonte de acción de la organización sindical, en tanto uno de los principales argumentos construidos para legitimar la decisión fue que era necesario generar nuevos recursos para sostener las prestaciones sociales, el mismo apareció más lejano, hipermediado. En una primera etapa la asociación entre mecanismos como la cuota de afiliación o los aportes empresarios y la función social del gremio era más directa, se recaudaba para brindar servicios a los trabajadores. En esta etapa, en cambio, si bien el gremio sostenía que los emprendimientos tenian como objetivo obtener recursos para continuar con las prestaciones, entre el mecanismo y el fin último intervenían un conjunto de mediaciones tan extenso y complejo que el fin declarado quedaba desdibujado.

La visión economicista, la ambición de poder y el pragmatismo se proyectaron en un plan de capitalización que se materializó en el holding empresarial y que encontró su límite inmediato en el poder adquisitivo del gremio y en la competencia de mercado, todo lo cual coadyuvó a liquidar los activos a partir de 2003.

Como segunda característica emerge que el plan de capitalización implicó la ampliación del patrimonio, donde el mismo no constituía un fondo de consumo destinado al uso de los trabajadores (como los campos de recreo y los hoteles), sino un capital fijo montado para captar más valor. En este sentido se esperaba que los mecanismos de reproducción material de carácter empresario -cuyos determinantes son ajenos al empleo, los salarios y la negociación colectiva- tengan efectos expansivos, pero no fundados en el consumo sino en la valorización.

La tercera característica que aparece es que los mecanismos a través de los cuales el gremio intentaba expandirse se disociaron de la reproducción de los trabajadores representados. Si bien en muchos casos los nuevos mecanismos reproductivos se montaron sobre estructuras preexistentes ligadas a los servicios sociales, éstas quedaron desarticuladas de los trabajadores, en tanto que ya no tenían como objetivo inmediato satisfacer crecientes necesidades sociales, sino apropiarse de diferentes formas de plusvalía.

Abundaron estas prácticas. La empresa de medicina prepaga se proyectaba construir sobre la estructura nacional de la obra social y la 
agencia de turismo sobre las filiales locales. Por su parte la AFJP además de utilizar a los gremios de base como sucursales de atención al cliente, apeló al fondo compensador constituido en el pasado sobre la solidaridad intergeneracional, como plataforma de un negocio financiero fundado en el ahorro personal.

La relación de los trabajadores con estas estructuras y su identidad con respecto al gremio se complejizó. Además de afiliados, los dirigentes apelaron a ellos como propietarios directos (de acciones del PPP) o diferidos (en tanto miembros de la organización) de las empresas. Al mismo tiempo se convertían en clientes de las unidades de negocios, aunque no necesariamente cautivos, dado que sólo un número menor de trabajadores adhirió a la AFJP sindical, mientras que la ART y los tickets canasta sólo fueron contratados por algunas empresas del sector.

La adquisición de las compañias eléctricas supuso además que la relación de representantes-representados conviviera con otra que objetivamente se le oponía, la de empleadores-empleados. No se disponen de datos concretos que evidencien qué características asumió la Federación como patronal a través de sus representantes (los dirigentes de sindicatos de base) en los directorios empresarios. Existe la posibilidad de que la adquisición de empresas haya transformado a la Federación en un empleador comparativamente más benévolo con los trabajadores, lo que otorga matices y argumentos legitimadores a la estrategia, sin embargo, nada de eso niega la contradicción intrínseca que tal fenómeno implicaba, la que se establece entre representar trabajadores y personificar capital.

La operación de la ART fue otro caso que planteó con claridad la contradicción dentro del gremio. Al tiempo que participaba en las comisiones de higiene y seguridad como representante de los trabajadores, desde la aseguradora-aunque su negocio anclaba en la esfera financiera- debía minimizar la cobertura de accidentes y enfermedades laborales.

Por este camino, el intento de sostenerse a través de emprendimientos empresarios, se distanció de la lucha por la expansión del consumo de los trabajadores.

Atravesada por las contradicciones, la FATLYF sostuvo puestos de trabajo y adquirió empresas menores, de dudosa rentabilidad. Pero también, como se viene argumentando, intervino en negocios que nada tenían que ver con proveer servicios a los trabajadores, sino que por el contrario implicaron su mercantilización.

Todo este proceso se produjo además sobre una base diezmada, en tanto que con las privatizaciones miles de trabajadores que habian contribuido al sostenimiento de la organización fueron despojados de sus puestos de trabajo y de la posibilidad de acceder a los beneficios 
de la membresía sindical. Similar suerte sufrieron los tercerizados a los que el gremio contribuyó a organizar y legitimar.

El sindicato intentó articular a través del discurso lo que materialmente estaba desarticulado. En esta clave se lee la presentación de los emprendimientos empresarios como una expresión más del sindicalismo múltiple, operación que coincide con una de las interpretaciones del fenómeno en términos de "business unionism" o prolongación del sindicalismo de servicios.

Como hemos reseñado, las lecturas sobre el sindicalismo empresarial vieron en él una respuesta que iba en línea con tradiciones y prácticas preexistentes asociadas a un sindicalismo corporativo y burocrático, que negocia prerrogativas con el Estado y que actúa como una agencia de servicios sociales.

Nuestra perspectiva no niega estas características. Sí en cambio da cuenta de que en las mismas no se aloja la novedad del fenómeno, que todas ellas remiten a rasgos de continuidad y que por tanto las interpretaciones dominantes son al menos simplificadoras. Tras transitar mayores o menores niveles de análisis la explicación a la que llegan no dista de una apreciación más ligera que a priori puede catalogar a la estrategia como una reacción propia de la burocracia sindical que conduce las organizaciones.

Sobre este punto, teniendo como referencia el caso del gremio eléctri$\mathrm{co}$, es necesario hacer algunas reflexiones sobre los debates convocados en torno a la multiplicidad de prácticas al que el atractivo concepto de "burocracia sindical" es subsumido. Uno de esos debates refiere al lugar de los sindicatos en una formación social capitalista; otro se preocupa por la democracia sindical, los procesos internos de las organizaciones y la relación dirigentes-bases.

En relación al primero, LYF CF históricamente se constituyó como un gremio que bogó por la conciliación de clases y la integración social; siendo representante de una aristocracia obrera definió intereses microcorporativistas y fue vanguardia de un modelo de organización de carácter mutualista; a diferencia del caso de LYF Córdoba con la conducción de Tosco, en el que esa misma aristocracia se presentó como vanguardia de un sindicalismo de liberación (Iñigo Carrera, Grau y Martí, 2006). $\mathrm{El}$ sindicalismo empresarial y el acompañamiento a las privatizaciones puede leerse en esta clave de integración, negociación, pragmatismo que es histórica en el gremio capitalino, y que en la coyuntura de reforma de mercado y neoliberalismo de los años 90 se expresó en esos términos. Por tanto, no habría acá mayores fisuras, sino rasgos de continuidad.

Con respecto al segundo debate, LYF CF es desde sus inicios un gremio verticalista y disciplinado, en el cual las decisiones son tomadas por la dirigencia y refrendadas por las bases, en ocasiones con dificulta- 
des. ${ }^{7}$ Esto incluso fue así durante la última dictadura militar, cuando la conducción desplazada del gremio organizó las acciones de resistencia de octubre de 1976 y febrero de 1977 (Ghigliani, 2012; Haidar, 2015a). En este sentido también puede entenderse que el acompañamiento a la privatización y el sindicalismo empresarial fueron decisiones adoptadas por la cúpula y acatadas por las bases (aunque hacia el interior de la FATLYF hubo disputas y disciplinamiento, como quedó evidenciado con la expulsión del gremio de Mar del Plata). Que este proceso pudo realizarse gracias a la connivencia de la conducción sindical no hay dudas, pero acá tampoco se presentarían desplazamientos sino una linea de continuidad.

Estas precisiones sobre el caso nos llevan a considerar que nociones como las de un sindicalismo corporativista, pragmático, negociador o burocrático, constituyen presupuestos analíticos que asumimos como datos, pero que no tienen carácter explicativo a fin de dar cuenta de la naturaleza y especificidad del fenómeno estudiado. Por el contrario, pretender explicarlo por los atributos propios del gremio sería incurrir en una operación tautológica.

En otros términos, LYF CF frente a las reformas de mercado de los años 90 respondió como un gremio corporativista, pragmático, negociador, verticalista. Pero el análisis histórico evidencia que esos atributos ya lo acompañaban en etapas previas y que por tanto no son ellos los que pueden conducir a identificar y entender las transformaciones que el sindicalismo empresarial expresa. En cambio, nuestra perspectiva identificó la vida material de la organización como la dimensión que -analizada históricamente- da cuenta de las nuevas características del fenómeno.

En esta clave advertimos que los rasgos que asumieron los mecanismos reproductivos en esta etapa (1992-2003) difirieron cualitativamente de aquellos que primaron bajo el llamado sindicalismo múltiple (1943-1976).

Mientras que entonces predominaron las relaciones sociales simples

7. Según está documentado en las publicaciones de LYF CF y de acuerdo al relato de ex dirigentes, hubo asambleas en que las bases rechazaron las propuestas de la conducción (es famosa la asamblea general del gremio de 1975 realizada en la cancha de Independiente con cerca de 30.000 trabajadores que "le rechazó el convenio a Smith"). En entrevistas realizadas durante 2013 a los dirigentes gremiales acerca de los modos en que se toman las decisiones, la respuesta fue que lo hace la conducción y que los trabajadores acatan. Debe señalarse, sin embargo, que LYF CF es un gremio con alta presencia sindical en los lugares de trabajo, con una estructura formada por delegados y subdelegados gremiales, delegados militantes, representantes y miembros del comité de lugar. Asimismo, se respetan las instancias orgánicas definidas en los estatutos. Todo esto exige complejizar la habitual caracterización de la burocracia sindical. 
(cuotas de afiliación, aportes de trabajadores y empleadores) que habilitaron el funcionamiento de otras más complejas (venta de mercancías vía cooperativas) pero con limites cuanti y cualitativos, bajo el sindicalismo empresarial la reproducción material del sindicato se autonomizó de las relaciones sociales simples y de sus determinantes (empleo sectorial, salarios y dinámica de la negociación) y se sostuvo sobre relaciones sociales complejas que implicaron la personificación de capital. En esta nueva etapa, a diferencia de la primera, el patrimonio no consistió en un fondo de consumo sino que se constituyó en capital con la intención de generar efectos expansivos fundados en la valorización. Por último, por primera vez se produjo una desarticulación entre la reproducción de la organización y la de los trabajadores, en tanto los mecanismos de reproducción material de la primera estaban disociados de la satisfacción de las necesidades de los segundos.

Este proceso estuvo atravesado por múltiples matices y contradicciones. No obstante, más allá de las mismas y de los alcances reales que tuvo la estrategia en términos de eficacia económica, ${ }^{8}$ es posible reconocer en los negocios empresarios mecanismos reproductivos que sostuvieron una etapa en la vida material de la organización que puede caracterizarse como de expansión capitalista (Haidar, 2015a), esto es, de acercamiento a la llamada economía politica del capital, aquella que tiene como fin la valorización y que da sentido al oxímoron "sindicalismo empresarial".

\section{Bibliografia}

De la Garza, Enrique (2001), "Introducción: las transiciones políticas en América Latina, entre el corporativismo sindical y la pérdida de imaginarios colectivos", en Enrique De la Garza (comp.), Los sindicatos frente a los procesos de transición politica, Buenos Aires: CLACSO, pp. 9-24.

Duarte, Marisa (2001), "Los efectos de las privatizaciones sobre la ocupación en las empresas de servicios públicos", Realidad Económica, ${ }^{\circ} 182$, Buenos Aires, pp. 32-60.

Etchemendy, Sebastián (2001), "Construir coaliciones reformistas: la política de las compensaciones en el camino argentino hacia la liberalización económica", Desarrollo Económico, n ${ }^{\circ} 160$, vol. 40, Buenos Aires, pp. 675-706.

8. En el 2003 la FATLYF realizó la última adquisición empresaria y comenzó un proceso de liquidación de sus negocios que se extendió hasta el 2010. En esta decisión se conjugaron un conjunto de factores: las políticas de gobierno orientadas a aumentar la intervención del Estado sobre la dinámica socioeconómica del país, la recomposición de determinantes como el empleo y el salario, y también los limites que encontró la organización frente a la competencia de mercado (Haidar, 2015a). 
Falcón, Ricardo (1984), Los origenes del movimiento obrero (1857-1899), Buenos Aires: CEAL.

Ghigliani, Pablo (2009), "Sindicatos y personificación de capital: acerca de la emergencia de un sindicalismo empresario en Argentina”, XXVII Congreso Latinoamericano de Sociologia, ALAS, Buenos Aires.

- (2012), "La resistencia de Luz y Fuerza a las políticas de la dictadura: los conflictos de 1976 y 1977", Historia Regional, Villa Constitución: Instituto Superior del Profesorado N 3 "Eduardo Lafferriere".

- y Julieta Haidar (2013), "Reformas de mercado y sindicalismo empresarial. El caso de Luz y Fuerza Capital Federal”, XI Congreso de ASET, Buenos Aires.

Ghigliani, Pablo, Juan Grigera y Alejandro Schneider (2012), "Sindicalismo empresarial. Problemas de conceptualización y alternativas teóricometodológicas", Revista Latino-americana de Estudos do Trabalho, año 17, $\mathrm{n}^{\circ}$ 27, Río de Janeiro, pp. 141-164.

Haidar, Julieta (2010), "Discusiones en torno al concepto de sindicalismo empresarial", IX Congreso Nacional y II Congreso Internacional sobre Democracia de la SAAP, Rosario.

- (2015a), "Continuidades y transformaciones en los mecanismos de reproducción material del sindicato Luz y Fuerza Capital Federal (1943-2003)", Tesis de Doctorado en Ciencias Sociales, UBA, inédita.

- (2015b), "Interpreting Argentine Business Unionism", Latin American Perspectives, vol. 42, $\mathrm{n}^{\circ}$ 2, Beverly Hills, pp. 60-73.

Harvey, David (1990), Los limites del capitalismo y la teoría marxista, México: FCE.

Horowitz, Joel (1988), "El impacto de las tradiciones anteriores a 1943 en el peronismo", en Juan Carlos Torre (comp.), La formación del sindicalismo peronista, Buenos Aires: Legasa, pp. 99-117.

Iñigo Carrera, Nicolás, María Isabel Grau y Analía Martí (2006), Agustín Tosco. La clase revolucionaria, Buenos Aires: Ediciones Madres de Plaza de Mayo.

Martuccelli, Danilo y Maristella Svampa (1997), La plaza vacía. Las transformaciones del peronismo, Buenos Aires: Losada.

Murillo, Victoria (1997), "La adaptación del sindicalismo argentino a las reformas de mercado en la primera presidencia de Menem", Desarrollo Económico, vol. 37, $\mathrm{n}^{\circ}$ 147, Buenos Aires, pp. 419-446.

- (2001), Sindicalismo, coaliciones partidarias y reformas de mercado en América Latina, Madrid: Siglo XXI.

Novick, Marta (1996), “¿Estrategia gremial o comportamiento defensivo? El destino de los sindicatos", Encrucijadas, año 2, n 4, Buenos Aires, pp. 34-41.

- (2001), "Nuevas reglas de juego en la Argentina, competitividad y actores sindicales", en Enrique De la Garza (comp.), Los sindicatos frente a los procesos de transición politica, Buenos Aires: CLACSO, pp. 25-46. 
Palomino, Héctor (1999), "Los sindicatos en la Argentina contemporánea", Nueva sociedad, $\mathrm{n}^{\circ}$ 169, Caracas, pp. 121-134.

Ranis, Peter (1995), "Challenges to Organized Labor in the Post-Industrial World: Argentina, Germany and the U.S.", York College and Graduate Center, CUNY, mimeo.

Titulo: The business unionism in the 90s. An approach from its materiality

Resumen: En los años 90, frente a las reformas de mercado, las organizaciones sindicales más poderosas de Argentina adoptaron la estrategia llamada "sindicalismo empresarial", que consistió en la participación activa en aquellas reformas. Las interpretaciones dominantes del fenómeno entendieron que se trataba de una respuesta que expresaba una continuidad con prácticas adaptativas y pragmáticas propias de la burocracia sindical.

En este trabajo, en cambio, consideramos que esas lecturas son reduccionistas y proponemos abordar el sindicalismo empresarial desde una perspectiva que examine la problemática de cómo una organización gremial se reproduce materialmente en distintas etapas históricas.

Para avanzar en esta propuesta estudiamos el caso del sindicato Luz y Fuerza Capital Federal (LYF CF) que fue paradigmático en el impulso de la estrategia empresarial.

Palabras clave: Sindicalismo empresarial - Reproducción material - Etapas históricas - Luz y Fuerza Capital Federal

Abstract: In the 90s, facing the market reforms, the most powerful unions in Argentina adopted a strategy called "business unionism", which consisted in an active participation in the reforms.

The dominant interpretations of the phenomenon understood that it was an answer that expressed continuity with typical adaptive and pragmatic practices of the union bureaucracy.

This paper, however, considers these interpretations reductionist and proposes to approach the business unionism from a perspective that examines the issue of how an union is materially reproduced at different historical stages.

To achieve this objective this paper analyzes the case of the union Luz y Fuerza Capital Federal (LYF CF) that was paradigmatic in the business strategy.

Key words: Business unionism - Material reproduction - Historical stages - Luz y Fuerza Capital Federal

Recepción: 3 de diciembre de 2015. Aprobación: 15 de marzo de 2016. 